\title{
Electron Transfer Reactions in Organic Chemistry. VII.* Oxidative Acetoxylation of Aromatic Compounds by Tungsten Hexachloride
}

\author{
LENNART EBERSON, ${ }^{* *}$ LENNART JÖNSSON and OWE SÄNNESKOG
}

Division of Organic Chemistry 3, Chemical Center, University of Lund, P.O. Box 124, S-221 00 Lund, Sweden

Tungsten hexachloride, a high-potential oxidant, causes fast oxidative acetoxylation of ring and/or a positions of aromatic compounds, even as difficultly oxidizable ones as mesitylene and $p$-xylene. Chlorination is a competing reaction which cannot be completely suppressed. The acetoxylation process in all likelihood proceeds via an electron transfer mechanism, involving initial formation of the radical cation of the substrate.

Tungsten hexachloride is a very strong one-electron oxidant [eqn. (1)] with an $E^{\circ}$ of 1.85-1.90 $\mathrm{V}$ vs. NHE (normal hydrogen electrode; all potentials given in this paper are referred to this standard) in dichloromethane ${ }^{1}$ or acetonitrile. ${ }^{2}$ A second electron can be added to hexachlorotungstate(V) ion [eqn. (2)], the $E^{\circ}$ value of this step being $0.55-0.60 \mathrm{~V}$.

$$
\begin{aligned}
& \mathrm{WCl}_{6}+\mathrm{e}^{-} \rightleftharpoons \mathrm{WCl}_{6}^{-} \\
& \mathrm{WCl}_{6}{ }^{-}+\mathrm{e}^{-} \rightleftharpoons \mathrm{WCl}_{6}^{2-}
\end{aligned}
$$

The high $E^{\circ}$ value of (1), in combination with a reasonably high solubility of tungsten hexachloride in organic media, makes this reagent an interesting candidate as oxidant toward organic compounds, especially difficultly oxidizable ones. To our knowledge, no studies designed to explore this aspect of $\mathrm{WCl}_{6}$ chemistry have been reported, but it has often been noted in connection with other studies that $\mathrm{WCl}_{6}$ rapidly oxidizes organic compounds like aliphatic amines ${ }^{3}$ and sulfides, ${ }^{4}$ pyridine ${ }^{5}$ (with oxidative coupling to yield 1-(4-pyridyl)pyridinium ion) and aromatic hydrocarbons ${ }^{6}$ (no products given) with oxidation potential lower than that of benzene. Benzene itself gives a charge-transfer complex. ${ }^{6}$ Toluene has been chlorinated by $\mathrm{WCl}_{6}$ in very low yield ${ }^{7}(2 \%, o / p$ ratio same as for molecular chlorination $=50 / 50$ ). It is also pertinent for the study to be presented here that $\mathrm{WCl}_{6}$ slowly oxidizes chloride ion to chlorine in organic media like methanol, 1,2dimethoxyethane, and acetonitrile. ${ }^{8}$ It is also sensitive to solvolysis in protic media (water, alcohols, carboxylic acids).

\footnotetext{
* Part VI. Eberson, L. and Radner, F. Acta Chem. Scand. B 38 (1984) 861.

** To whom correspondence should be addressed. 
In our continued studies on the electron transfer oxidation of aromatic compounds by high-valent metal complexes $\left[\mathrm{Ag}(\mathrm{II}),{ }^{9} \mathrm{Ce}(\mathrm{IV}),{ }^{10,11} \mathrm{Co}(\mathrm{III}),{ }^{12,13} \mathrm{Cu}(\mathrm{III}),{ }^{14} \mathrm{Mn}(\mathrm{IV}),{ }^{15}\right.$ $\mathrm{Ni}(\mathrm{IV})^{15}$ ], sulfate radical $^{16}$ or the anode, ${ }^{17,18}$ we now report an investigation of the phenomenology of $\mathrm{WCl}_{6}$ induced oxidative substitution of aromatic compounds. As model reaction oxidative acetoxylation [eqn. (3)] was chosen, since it is a characteristic and

$$
\mathrm{CH}_{3} \mathrm{ArH}+\mathrm{AcO}^{-} \rightarrow \mathrm{CH}_{3} \mathrm{ArOAc}+\mathrm{AcOCH}_{2} \mathrm{ArH}
$$

well studied ${ }^{9-20}$ electron transfer (ET) oxidation. The results obtained indeed classify $\mathrm{WCl}_{6}$ as an ET oxidant, although as expected concurrent chlorination makes it less useful from a practical point of view.

\section{RESULTS}

Exploratory experiments immediately showed that dichloromethane (which dissolves $c a$. $0.033 \mathrm{M} \mathrm{WCl}_{6}$ at room temperature) is the solvent of choice for $\mathrm{WCl}_{6}$ oxidations. It also turned out that chlorination was minimized by keeping as low a proportion of acetic acid and high concentration of alkali acetate as possible (see Table 1). Eventually, a suitable compromise was established between these conflicting (with respect to solubility) demands at $\mathrm{HOAc} / \mathrm{CH}_{2} \mathrm{Cl}_{2}=1 / 10$ with [MOAc] $=0.1 \mathrm{M}$. Potassium acetate was slightly better than sodium acetate in this respect, whereas tetrabutylammonium acetate as a nucleophile source did not effect acetoxylation under any of the conditions given in Table 1. Instead, complexes, presumably of the type $\mathrm{WCl}_{6-n}(\mathrm{AcO})_{n}$, precipitated during the work-up procedure. These were unstable in the solid phase and possessed none of the oxidizing power of $\mathrm{WCl}_{6}$.

The reactions could be run both with addition of the $\mathrm{WCl}_{6}$ solution in $\mathrm{CH}_{2} \mathrm{Cl}_{2}$ to a solution of the substrate (oxidant to substrate in a 1:4 molar ratio) in HOAc/KOAc or inversely, with almost identical results. With substrates of moderate $E^{\circ}\left(\mathrm{ArH}^{*} / \mathrm{ArH}\right)$, like 4-methoxytoluene $(1.82 \mathrm{~V}),{ }^{19}$ and naphthalene $(2.08 \mathrm{~V})^{20}$ the reaction proceeded at titration speed, but also more difficultly oxidizable substrates reacted relatively fast. In many cases, the inverse addition of the HOAc/substrate solution to the dark red-brown $\mathrm{WCl}_{6}$ solution produced a succession or rather remarkable colour changes: from red-brown to clear yellow, followed by a quick transformation to a dark blue-violet colloidal suspension ("Tungsten Blues"). The total reaction period varied from seconds (e.g., naphthalene) up to an hour (e.g., anisole $20 \mathrm{~min}$ and mesitylene $1 \mathrm{~h}$ ). For comparison, it can be mentioned that the solvent/nucleophile system without substrate added underwent slow reaction only (blue-violet colour after $6 \mathrm{~h}$ ). In mesitylene oxidation, the addition of chloride ion ( $\mathrm{LiCl})$ increases the yield of chlorination products (see Table 1). We also found that $\mathrm{WCl}_{6}$ slowly oxidizes chloride ion (added as $\mathrm{LiCl}$ ) to chlorine in $\mathrm{HOAc} / \mathrm{CH}_{2} \mathrm{Cl}_{2}$.

Table 2 shows the nature and absolute yields of products from nine substrates, each representing one or several typical aspects of ET behaviour. Yields were moderate at best, and it has not been possible to eliminate chlorination as a side-reaction. Apart from the compounds mentioned in Table 2, two arylacetic acids (4-methoxyphenyl- and phenylacetic acid) were tried; 4-methoxyphenylacetic acid gave $8 \%$ of 4-methoxybenzyl acetate and phenylacetic acid traces of benzyl acetate.

A characteristic feature of ET oxidation is the switch of reaction mode from substitution to coupling upon decreasing the nucleophilicity of the medium, e.g. by leaving out the added 
Table 1. Distribution between acetoxylation and chlorination in $\mathrm{WCl}_{6}$ induced oxidative substitution of aromatic compounds under different conditions.

\begin{tabular}{lclcc}
\hline & Ratio HOAcl & $\begin{array}{l}\text { Added } \\
\text { component }\end{array}$ & \multicolumn{2}{c}{ Percentage of } \\
\cline { 4 - 5 } Substrate & $\mathrm{CH}_{2} \mathrm{Cl}_{2}(\mathrm{v} / \mathrm{v})$ & (conc./M) & Acetoxylation & Chlorination \\
\hline Anisole & 0.33 & None & $<0.01$ & $>99.99$ \\
Anisole & 0.33 & NaOAc (0.1) & 66 & 34 \\
Anisole & 0.10 & NaOAc (0.1) & 81 & 19 \\
Anisole & 0.10 & KOAc (0.1) & 94 & 6 \\
Naphthalene & 0.33 & NaOAc (0.1) & 42 & 58 \\
Naphthalene & 0.19 & NaOAc (0.1) & 84 & 16 \\
Mesitylene & 0.33 & None & $<0.01$ & $>99.99$ \\
Mesitylene & 0.33 & NaOAc (0.1) & 10 & 90 \\
Mesitylene & 0.33 & NaOAc (0.2) & 23 & 77 \\
Mesitylene & 0.20 & NaOAc (0.2) & 42 & 58 \\
Mesitylene & 0.33 & NaOAc (0.4) & 27 & 73 \\
Mesitylene & 1.00 & NaOAc (0.6) & 16 & 84 \\
Mesitylene & 0.10 & NaOAc (0.1) & 57 & 43 \\
Mesitylene & 0.10 & KOAc (0.1) & 57 & 43 \\
Mesitylene & 0.10 & KOAc (0.2) & 57 & 43 \\
Mesitylene & 0.10 & KOAc (0.08) & 33 & 67 \\
& & LiCl (0.02) & & \\
Mesitylene & 0.10 & LiCl (0.1) & $<0.01$ & $>99.99^{a}$ \\
Mesitylene & 0.05 & NaOAc (0.05) & 53 & 47 \\
Mesitylene & 0.05 & KOAc (0.1) & 81 & 19 \\
Mesitylene & 0.01 & KOAc (0.02) & $<0.01$ & $>99.99$ \\
Hexamethylbenzene & 0.33 & NaOAc (0.1) & 33 & 67 \\
Hexamethylbenzene & 0.10 & NaOAc (0.1) & 33 & 67 \\
4-Methoxytoluene & 0.33 & NaOAc (0.1) & 33 & 67 \\
4-Methoxytoluene & 0.10 & NaOAc (0.1) & 40 & 60 \\
$p$-Xylene & 0.33 & NaOAc (0.1) & 32 & 68 \\
$p$-Xylene & 0.22 & NaOAc (0.18) & 28 & 72 \\
\hline
\end{tabular}

a $43 \%$ chloromesitylene and $0.3 \%$ side-chain chloride based on $2 \mathrm{WCl}_{6}$ per $\mathrm{ArX}$ formed.

nucleophile. ${ }^{12,17,19,21}$ This is most clearly brought out in anodic oxidation. ${ }^{17,19}$ This behaviour could be duplicated in $\mathrm{WCl}_{6}$ oxidation, although not as convincingly as desired. Thus, with mesitylene as substrate, $c a$. $1 \%$ of a coupling product (3,5-dimethylbenzyl-1,4,6trimethylbenzene, 1$)$ was detected in addition to chloromesitylene $(13 \%)$ when the reaction was carried out in neat $\mathrm{CH}_{2} \mathrm{Cl}_{2}$ or with $\mathrm{HOAc}$ replaced by $\mathrm{CF}_{3} \mathrm{COOH}$. Attempts to reach higher yields of 1 by increasing the substrate concentration $(2 \mathrm{M})$ were unsuccessful.

\section{DISCUSSION}

As seen from Tables 1 and 2, our first objective has been accomplished, namely to establish that $\mathrm{WCl}_{6}$ can induce oxidative acetoxylation of aromatic compounds according to eqn. (3). Moreover, its high oxidizing power makes acetoxylation possible even with substrates as difficultly oxidizable as $p$-xylene $\left(E^{\circ}=2.33 \mathrm{~V}\right)$ and mesitylene $\left(E^{\circ}=2.30 \mathrm{~V}\right)$, in spite of the fact that other competing reactions can take place (see below). As might be expected for an Acta Chem. Scand. B 39 (1985) No. 2 
Table 2. Nature and yields of products ${ }^{a}$ formed in the $\mathrm{WCl}_{6}$ induced oxidative substitution of aromatic compounds in $\mathrm{CH}_{3} \mathrm{COOH} / \mathrm{CH}_{2} \mathrm{Cl}_{2}(1: 10, \mathrm{v} / \mathrm{v})$ containing $\mathrm{NaOAc}(0.1 \mathrm{M})$ at room temperature.

\begin{tabular}{|c|c|c|}
\hline Substrate $\left(E^{\circ} / \mathrm{V}\right)^{b}$ & $\begin{array}{l}\text { Acetoxylation product(s) } \\
\text { (yield/\%) }\end{array}$ & $\begin{array}{l}\text { Chlorination product(s) } \\
\text { (yield/\%) }\end{array}$ \\
\hline Mesitylene (2.30) & 3,5-Dimethylbenzyl acetate (16.1) & $\begin{array}{l}\text { Chloromesitylene (11.2) } \\
\text { 3,5-Dimethylbenzyl chloride (1.7) }\end{array}$ \\
\hline Biphenyl (2.19) & $\begin{array}{l}\text { 2-Acetoxybiphenyl (2) } \\
\text { 4-Acetoxybiphenyl (8) }\end{array}$ & 4-Chlorobiph \\
\hline Naphthalene (2.08) & $\begin{array}{l}\text { 1-Naphthyl acetate }(37.6) \\
\text { 2-Naphthyl acetate }(<0.1)\end{array}$ & $\begin{array}{l}\text { 1-Chloronaphthalene }(7) \\
\text { 2-Chloronaphthalene }(<0.1)\end{array}$ \\
\hline Anisole (2.15) & $\begin{array}{l}\text { 2-Methoxyphenyl acetate (13) } \\
\text { 4-Methoxyphenyl acetate (25) }\end{array}$ & $\begin{array}{l}\text { 2-Chloroanisole (5) } \\
\text { 4-Chloroanisole (4) }\end{array}$ \\
\hline $\begin{array}{l}\text { Hexamethylbenzene } \\
\text { (1.85) }\end{array}$ & Pentamethylbenzyl acetate (11) & Pentamethylbenzyl chloride (22) \\
\hline $\begin{array}{l}\text { 4-Methoxytoluene } \\
\text { (1.82) }\end{array}$ & $\begin{array}{l}\text { 4-Methoxybenzyl acetate (8) } \\
\text { 3-Acetoxy-4-methoxytoluene (2) }\end{array}$ & $\begin{array}{l}\text { 4-Methoxybenzyl chloride (14) } \\
\text { 3-Chloro-4-methoxytoluene (3) }\end{array}$ \\
\hline$p$-Xylene (2.33) & $\begin{array}{l}\text { 4-Methylbenzyl acetate } \\
\text { Acetoxy-1,4-dimethyl- } \\
\text { benzene }^{c}\end{array}$ & 4-Methylbenzyl chloride ${ }^{c}$ \\
\hline $\begin{array}{l}\text { Benzene (3.03) } \\
\text { 4-Fluoroanisole (2.10) }\end{array}$ & $\begin{array}{l}\text { No acetate formed } \\
\text { 4-Methoxyphenyl acetate (5) } \\
\text { 2(?)-Acetoxy-4-fluoroanisole (9) }\end{array}$ & $\begin{array}{l}\text { Chlorobenzene } \\
\text { 2(?)-Chloro-4-fluoroanisole (3.5) }\end{array}$ \\
\hline
\end{tabular}

${ }^{a}$ Calculated on the basis of $2 \mathrm{WCl}_{6}$ per ArX formed. ${ }^{b} E^{\circ}$ values were taken from a compilation of $\mathrm{Ref}$. 20 or calculated from eqn. (9) in this review. ${ }^{c}$ Trace amounts.

ET mechanism, benzene with $E^{\circ}>3.0 \mathrm{~V}$ does not undergo acetoxylation, since a non-bonded $\mathrm{ET}$ step between $\mathrm{WCl}_{6}$ and benzene would be too strongly endergonic. Using eqn. 70 of Ref. 20 , one can estimate a rate constant for this process to be $<0.03 \mathrm{M}^{-1} \mathrm{~s}^{-1}$ (putting $k_{\mathrm{d}}=2 \times 10^{10} \mathrm{M}^{-1} \mathrm{~s}^{-1}, A=0.2, \Delta G^{\ddagger}(0)=3.8 \mathrm{kcal} \mathrm{mol}^{-1}$, and $\Delta G^{\circ \prime}=17 \mathrm{kcal} \mathrm{mol}^{-1}$ ), whereas for $p$-xylene and mesitylene the rate constant is calculated to be $c a .5 \times 10^{3} \mathrm{M}^{-1} \mathrm{~s}^{-1}$ (same $k_{\mathrm{d}}$ and $A$ as above, $\Delta G^{*}(0)=6.25 \mathrm{kcal} \mathrm{mol}^{-1 *}$ and $\Delta G^{\circ \prime}=7 \mathrm{kcal} \mathrm{mol}^{-1}$ ). Thus we suggest that $\mathrm{WCl}_{6}$ induced acetoxylation is analogous to other acetoxylations ${ }^{9-20}$ brought about by high-potential oxidants or the anode [an ECE mechanism, see eqns. (4-7)].

$$
\operatorname{ArH}\left(\mathrm{Ar}^{\prime} \mathrm{CH}_{3}\right)+\mathrm{WCl}_{6} \rightleftharpoons \mathrm{ArH}^{+}\left(\mathrm{Ar}^{\prime} \mathrm{CH}_{3}{ }^{+}\right)+\mathrm{WCl}_{6}^{-}
$$

$$
\mathrm{ArH}^{\cdot+}\left(\mathrm{Ar}^{\prime} \mathrm{CH}_{3}{ }^{+}\right)+\mathrm{AcO}^{-} \rightarrow \stackrel{\mathrm{Ar}}{\mathbf{H}}-\mathrm{OAc}\left(\mathrm{Ar}^{\prime} \mathrm{CH}_{2}{ }^{-}\right)+\mathrm{AcOH}
$$

* The reorganization energy $(\lambda)$ of methylbenzene oxidation is $c a .35 \mathrm{kcal} \mathrm{mol}^{-1} .22$ 


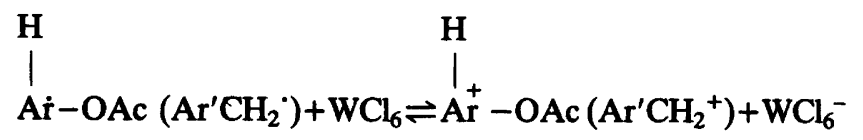

$$
\stackrel{+}{\mathrm{Ar}}-\mathrm{OAc}\left(\mathrm{Ar}^{\prime} \mathrm{CH}_{2}^{+}\right) \stackrel{\mathrm{AcO}^{-}}{\longrightarrow} \mathrm{ArOAc}\left(\mathrm{Ar}^{\prime} \mathrm{CH}_{2} \mathrm{OAc}\right)
$$

Before we discuss more detailed arguments in support of this suggestion, it is necessary to deal with the concurrent chlorination process. Two principally different types of chlorination mechanisms may be envisaged, namely a radical cation mediated one, ${ }^{23,24}$ analogous to the acetoxylation mechanism of eqns. 4-7, and one proceeding via chlorine, generated by $\mathrm{WCl}_{6}$ oxidation of chloride ion. The same mechanistic dichotomy pervades all discussions of anodic aromatic chlorination in chloride ion containing electrolytes, ${ }^{25}$ and it has not been possible to unambiguously distinguish between these two mechanisms.

Both demand a source of chloride ion, and it is logical to assume that this becomes available by relatively fast ligand exchange, [eqn. (8)]. By analogy with similar trans-

$$
\mathrm{WCl}_{6}+\mathrm{AcO}^{-} \rightleftharpoons \mathrm{WCl}_{5} \mathrm{OAc}+\mathrm{Cl}^{-}
$$

formations of other metal chlorides, it is also reasonable to assume that the new tungsten species is a weaker oxidant, maybe to the extent that it does not participate in further oxidation. In this extreme situation, in total $3 \mathrm{~mol}$ of $\mathrm{WCl}_{6}$ will be needed to produce $1 \mathrm{~mol}$ of monochlorinated product, since $2 \mathrm{~mol}$ are necessary for the chlorination process in itself, irrespective of the mechanism. In the second extreme, the effect of ligand exchange may not be detrimental to the oxidizing power of the W(VI) species, and then only two mol of $\mathrm{WCl}_{6}$ are needed for each monochloro product.

Apart from the difficulty of defining the stoiechiometry of the chlorination process, another source of uncertainty is the precipitation of Tungsten Blues. This mixed valence compound is described as a W(VI)/W(V) oxo complex but little is known about its exact composition. ${ }^{26}$ It can only be stated with certainly that the formation of Tungsten Blues must lead to loss of oxidant in the W(VI) state; hence all absolute yields reported are minimum yields but not really indicative of the efficiency of the reaction.

The closest chemical analogy to the $\mathrm{WCl}_{6}$ promoted chlorination process is $\mathrm{Co}$ (III) (as trifluoroacetate or acetate) induced chlorination in trifluoroacetic ${ }^{24}$ or acetic acid, ${ }^{23}$ respectively, in the presence of $\mathrm{LiCl}$. Of particular interest was the isolation of side-chain chlorination products besides nuclear chloro derivatives. Generally, side-chain chlorination is not found in chlorination by molecular chlorine, be it in the homogeneous ${ }^{27}$ or anodic variety. ${ }^{25}$ In both cases referred to above, the mechanism was considered to be radical cation mediated, the radical cation being either attached by $\mathrm{Cl}^{-}$at a ring position or an $\alpha$ proton abstracted by a base to give the benzylic radical. The alternative mechanisms, ionic nuclear chlorination and radical chain $\alpha$ chlorination were ruled out for reactivity reasons.

Considering the totality of available data for different types of oxidative aromatic chlorination, we find it difficult to favour one mechanism over the other in the $\mathrm{WCl}_{6}$ case. The few diagnostic criteria that can be used ( $\alpha /$ nuclear ratios, $o / p$ ratios) are too vague to be of any significance. We therefore presently leave this problem aside and concentrate on the acetoxylation process, for which a more clear-cut case can be made.

Acta Chem. Scand. B 39 (1985) No. 2 
Table 3. Isomer ratios in oxidative acetoxylation, using different reagents.

\begin{tabular}{|c|c|c|c|c|}
\hline \multirow[b]{2}{*}{ Reagent } & \multirow[b]{2}{*}{ Substrate } & \multicolumn{3}{|c|}{ Ratio } \\
\hline & & $\begin{array}{c}\text { Nuclear/ } \\
\text { side-chain }\end{array}$ & $\begin{array}{c}o / p \text { or } \\
1-/ 2-\end{array}$ & Ref. \\
\hline $\begin{array}{l}\mathrm{WCl}_{6} \text { in } \mathrm{HOAc} / \mathrm{CH}_{2} \mathrm{Cl}_{2} \\
(1 / 10), 0.1 \mathrm{M} \mathrm{NaOAc} \\
\text { at } 20^{\circ} \mathrm{C}\end{array}$ & $\begin{array}{l}\text { Anisole } \\
\text { Biphenyl } \\
\text { Naphthalene } \\
\text { Mesitylene } \\
\text { p-Xylene } \\
\text { 4-Methoxytoluene }\end{array}$ & $\begin{array}{c}<0.01 \\
3.0 \\
0.25\end{array}$ & $\begin{array}{r}0.52 \\
0.27 \\
>350\end{array}$ & \\
\hline $\begin{array}{l}\text { Pt anode in HOAc, } \\
0.5 \mathrm{M} \mathrm{NaOAc} \text { at } \\
20^{\circ} \mathrm{C}\end{array}$ & $\begin{array}{l}\text { Anisole } \\
\text { Biphenyl } \\
\text { Naphthalene } \\
\text { Mesitylene } \\
\text { p-Xylene }^{b} \\
\text { 4-Methoxytoluene }\end{array}$ & $\begin{array}{l}4.4^{a, b} \\
0.9 \\
0.04\end{array}$ & $\begin{array}{l}2.31 \\
0.46 \\
24\end{array}$ & $\begin{array}{l}18 \\
18 \\
18 \\
17 \\
28 \\
18\end{array}$ \\
\hline $\begin{array}{l}\mathrm{Pt} \text { anode in } \mathrm{CH}_{2} \mathrm{Cl}_{2} \text {, } \\
\text { ca. } 0.1 \mathrm{M} \\
\mathrm{Bu}_{4} \mathrm{~N}(\mathrm{AcO})_{2} \mathrm{H}\end{array}$ & $\begin{array}{l}\text { Anisole } \\
\text { Naphthalene } \\
p \text {-Xylene }\end{array}$ & $0.8^{d}$ & $>200^{1.10^{c}}$ & $\begin{array}{l}29 \\
29 \\
29\end{array}$ \\
\hline $\begin{array}{l}\mathrm{Ag}(\mathrm{II}) \text { in KOAc, } \\
0.5 \mathrm{M} \mathrm{NaOAc} \text { at } \\
40^{\circ} \mathrm{C}\end{array}$ & $\begin{array}{l}\text { Anisole } \\
\text { Biphenyl } \\
\text { Naphthalene } \\
\text { Mesitylene } \\
\text { 4-Methoxytoluene }\end{array}$ & $\begin{array}{c}2.3 \\
<0.01\end{array}$ & $\begin{array}{l}2.16 \\
0.27 \\
19\end{array}$ & $\begin{array}{l}9 \\
9 \\
9 \\
9 \\
9\end{array}$ \\
\hline $\begin{array}{l}\mathrm{K}_{5}\left[\mathrm{Co}(\mathrm{III}) \mathrm{W}_{12} \mathrm{O}_{40}\right], \\
11 \mathrm{H} \mathrm{O} \text { in } \mathrm{HOAc} / \mathrm{H}_{2} \mathrm{O} \\
(4 / 1, \mathrm{v} / \mathrm{v}), 0.1 \mathrm{M} \\
\mathrm{KOAc} \text { at } 102^{\circ} \mathrm{C}\end{array}$ & $\begin{array}{l}\text { Anisole } \\
\text { Biphenyl } \\
\text { Naphthalene } \\
\text { Mesitylene } \\
\text { p-Xylene } \\
\text { 4-Methoxytoluene }\end{array}$ & $\begin{aligned} & 0.41^{e} \\
< & 0.01 \\
< & 0.01\end{aligned}$ & $\begin{array}{l}1.3 \\
0.19 \\
99\end{array}$ & $\begin{array}{l}12 \\
12 \\
12 \\
12 \\
12 \\
12\end{array}$ \\
\hline $\begin{array}{l}\left(\mathrm{NH}_{4}\right)_{6}\left[\mathrm{Ni}(\mathrm{IV}) \mathrm{Mo}_{9} \mathrm{O}_{32}\right] \\
6 \mathrm{H}_{2} \mathrm{O} \text { in } \mathrm{HOAc}, 0.5 \mathrm{M} \\
\mathrm{KOAc} \text { at } 118^{\circ} \mathrm{C}\end{array}$ & $\begin{array}{l}\text { Anisole } \\
\text { Biphenyl } \\
\text { 4-Methoxytoluene }\end{array}$ & $<0.01$ & $\begin{array}{l}1.3 \\
0.22\end{array}$ & $\begin{array}{l}15 \\
15 \\
15\end{array}$ \\
\hline $\mathrm{Ce}(\mathrm{IV})$ in HOAc & $\begin{array}{l}\text { Anisole } \\
\text { Naphthalene } \\
\text { Mesitylene }\end{array}$ & $\approx 0.7^{\mathrm{g}}$ & $\begin{array}{c}0.82^{g} \\
24^{f}, 19^{g}\end{array}$ & $\begin{array}{l}29 \\
31 \\
10\end{array}$ \\
\hline $\begin{array}{l}\mathrm{SO}_{4}{ }^{-} \text {in HOAc } \\
\text { at } 113^{\circ} \mathrm{C}\end{array}$ & $\begin{array}{l}\text { Naphthalene } \\
\text { Mesitylene } \\
p \text {-Xylene }\end{array}$ & $\begin{array}{l}2.0^{i} \\
0.11^{i}\end{array}$ & $13^{h}$ & $\begin{array}{l}32 \\
16 \\
16\end{array}$ \\
\hline
\end{tabular}

${ }^{a}$ At a carbon anode the ratio is $>20 .{ }^{b} \mathrm{NaOAc}, 1.0 \mathrm{M}^{c}{ }^{c}$ At a graphite anode, $0.85 .{ }^{d}$ Excluding the concurrent formation of aldehyde and benzyl alcohol, ${ }^{e}$ Without KOAc added, $\approx 0.01 .{ }^{f} \mathrm{Ce}(\mathrm{OAc})_{4}$ at $70-80^{\circ} \mathrm{C} .{ }^{8}$ Cerium ammonium nitrate at $50{ }^{\circ} \mathrm{C}$. ${ }^{h}$ In the presence of $0.8 \mathrm{M}$ KOAc. ${ }^{i}$ With $10 \%$ trifluoroacetic acid present.

Table 3 compares nuclear/side-chain and/or o/p (or 1-/2-) isomer ratios for oxidative acetoxylation by $\mathrm{WCl}_{6}$ and other high-potential oxidants, for which there is reasonable or overwhelming support in favour of the ECE mechanism [eqns. (4-7)]. The latter range from compulsory ET mechanisms (at the anode), to kinetically established ones (12-tungstocobalt(III)ate ${ }^{13}$ and $\mathrm{Ce}(\mathrm{IV})^{33}$ ) and to cases where there is sufficiently close similarity with proven ECE acetoxylation mechanisms. As seen from Table 3, the pattern of 
isomer ratios is not uniform; isomer ratios vary with the nature of the oxidant in a way that presently is not very well understood. ${ }^{11}$

A reagent that can be described as a "pure" ET oxidant, is the $\mathrm{Co}$ (III) $\mathrm{W}_{12} \mathrm{O}_{40}{ }^{5-}$ ion [abbreviated $\mathrm{Co}$ (III)W]. This species has the $\mathrm{Co}$ (III) center buried deeply inside an intricate arrangement of $\mathrm{WO}_{6}$ octahedra, and exposes only inert oxygen atoms (less basic than even perchlorate oxygens) toward the solution. ${ }^{13}$ Thus any ET reaction of Co(III)W must be of the non-bonded type and produce the radical cation (radical) in as unperturbed state as is possible, apart from the electrostatic interaction between $\mathrm{Co}(\mathrm{II}) \mathrm{W}^{6-}$ and the radical cation (cation) as it has been formed. This complication should, however, be less serious than a direct interaction between an intermediate and a metal center.

Considering $\mathrm{Co}(\mathrm{III}) \mathrm{W}$ oxidation as the purest possible ET mechanism ${ }^{34}$ the $\mathrm{WCl}_{6}$ reaction deviates significantly on three points, namely the high nuclear $/ \alpha$ ratio in the acetoxylation of $p$-xylene and $p$-methoxytoluene and the low ratio for mesitylene. The latter compound is known for a consistently high nuclear reactivity in oxidative acetoxylation ${ }^{17}$ (and coupling), and there is no satisfactory explanation of the deviating behaviour of the $\mathrm{WCl}_{6}$ reaction. One might quote the temperature difference $(\mathrm{ca} .80 \mathrm{~K})$ as one possible cause of the reactivity difference, but then it remains to be explained why the selectivity toward side-chain substitution should change in opposite directions for mesitylene and $p$-xylene/4methoxytoluene, respectively. The same trend is seen upon comparing $\mathrm{WCl}_{6}$ and anodic acetoxylation.

Coupling (dehydrodimerization) of aromatic compounds is a common reaction, methylaromatic compounds normally giving both biaryl and diphenylmethane type coupling products. ${ }^{17,19} \mathrm{It}$ is favoured by high (above $1 \mathrm{M}$ ) substrate concentrations and known to give low or very low yields at concentrations around or lower than $0.1 \mathrm{M}$. It is therefore not surprising that mesitylene gives only $c a .1 \%$ of the dehydrodimer $(1)$ by $\mathrm{WCl}_{6}$ oxidation in the absence of any strong nucleophile. Even in the presence of a high ( $2 \mathrm{M})$ mesitylene concentration it was not possible to increase the yield of 1 . Other reagents that have been used to couple mesitylene give the following results in the few cases which have been run at low substrate concentrations (reagent, [substrate]/M, yield of $1+$ bimesityl/\%): $\mathrm{Cu}$ (III) in TFA, 0.2, 5.1; ${ }^{14} \mathrm{SO}_{4}{ }^{-}$in HOAc/TFA, 0.2, trace; ${ }^{16} \mathrm{Pt}$ anode in $\mathrm{CH}_{2} \mathrm{Cl}_{2} / \mathrm{Bu}_{4} \mathrm{NBF}_{4}, 0.2,1 .{ }^{35}$ Again, we might ponder the fact that the dehydrodimer from the $\mathrm{WCl}_{6}$ oxidation of mesitylene is of the diphenylmethane type (in acetoxylation this behaviour corresponds to the exclusive formation of the $\alpha$ acetate; see Table 2), while in other cases the most often encountered or predominant dehydrodimer is bimesityl, the biaryl coupling product.

A characteristic ET process is the so-called $\mathrm{S}_{\mathrm{ON}} 2$ reaction ${ }^{36-38}$ [eqn. (9)] which is an aromatic radical chain substitution process of the same type as the $S_{\mathrm{RN}} 1$ reaction, except that it needs oxidative stimulation by a high potential reagent in the initiation step, formation of a radical cation from the starting compound. 4-Fluoroanisole/acetate ion is a model reactant pair for an $\mathrm{S}_{\mathrm{ON}} 2$ process, the reaction having been initiated by the anode, ${ }^{36} \mathrm{Ag}$ (II), ${ }^{9}$ $\mathrm{Co}(\mathrm{III}) \mathrm{W}^{12}$ and photons. ${ }^{39}$ As seen from Table $2, \mathrm{WCl}_{6}$ induces the same reaction which provides additional support for the ET oxidizing nature of $\mathrm{WCl}_{6}$.

$$
\begin{aligned}
& \mathrm{ArX}+\mathrm{Nu}^{-} \stackrel{\text { Oxidant }}{\longrightarrow} \mathrm{ArNu}+\mathrm{X}^{-} \\
& \mathrm{X}=\mathrm{F}, \mathrm{Cl} \\
& \mathrm{Nu}^{-}=\mathrm{AcO}^{-}, \mathrm{CN}^{-}, \mathrm{H}_{2} \mathrm{O}
\end{aligned}
$$




\section{EXPERIMENTAL}

Materials. Tungsten hexachloride (Fluka, pract., 90-95\%) was used without further purification. All alkali metal salts were dried overnight at $120^{\circ} \mathrm{C}$. The dichloromethane was dried over molecular sieves $(3 \AA)$. All chemicals used in this investigation were either of the highest quality commercially available or prepared according to known methods described in earlier work. $9,16-18$

Oxidation procedure. A solution of $\mathrm{WCl}_{6}\left(1 \mathrm{mmol}\right.$ in $50 \mathrm{ml}$ of $\left.\mathrm{CH}_{2} \mathrm{Cl}_{2}\right)$ was mixed with a solution of the aromatic compound and alkali metal salt in glacial acetic acid. This solution was stirred at room temperature until the colour changed to blue-violet. This mixture was worked up by addition of saturated sodium hydrogen carbonate solution, followed by dichloromethane extraction and GLC analysis.

Analysis. Yields and isomer distribution were determined using a Varian 1400 gas chromatograph equipped with an electronic integrator (Hewlett Packard $3380 \mathrm{~A}$ ) on a 2 $\mathrm{m} \times 3 \mathrm{~mm} 5 \%$ NPGS on Chromosorb $\mathrm{W}$ column and a $2 \mathrm{~m} \times 3 \mathrm{~mm} 3 \%$ OV 101 on Chromosorb $\mathrm{Q}$ column. The yield was determined using an internal standard (biphenyl, bimesitylene and pentamethylbenzyl acetate) calibrated against authentic samples. The identification of the products was based on GLC-MS comparison (Finnigan 4021 instrument) with authentic samples.

Acknowledgement. Financial support from the Swedish Natural Science Research Council is gratefully acknowledged.

\section{REFERENCES}

1. Gilet, M., Mortreux, A., Folest, J.-C. and Petit, F. J. Am. Chem. Soc. 105 (1983) 3876.

2. Hagedorn, H.F., Iwamoto, R.T. and Kleinberg, J. J. Electroanal. Chem. 46 (1973) 307.

3. Brisdon, B.J., Fowles, G.W.A. and Osborne, B.P. J. Chem. Soc. (1962) 1330; Nugent, W.A. and Harlow, R. Inorg. Chem. 19 (1980) 777.

4. Boorman, P.M., Chivers, T. and Mahadev, K.N. Can. J. Chem. 53 (1975) 383; 55 (1977) 869; J. Chem. Soc. Chem. Commun. (1974) 502.

5. McCarley, R.E. and Brown, T.M. Inorg. Chem. 3 (1964) 1232.

6. Hammond, P.R. and McEwan, W.S. J. Chem. Soc. (1971) 3812.

7. Commandeur, R., Mathais, H., Raynier, B. and Waegell, B. Nouv. J. Chim. 3 (1979) 385.

8. Seifert, H.-J., Kiewich, B. and Wüsteneck, A. Z. Anorg. Allg. Chem. 431 (1977) 117.

9. Nyberg, K. and Wistrand, L.-G. Acta Chem. Scand. B 29 (1975) 629; J. Org. Chem. 43 (1978) 2613.

10. Eberson, L. and Oberrauch, E. Acta Chem. Scand. B 33 (1979) 343.

11. Baciocchi, E., Eberson, L. and Rol, C. J. Org. Chem. 47 (1982) 5106.

12. Eberson, L. and Wistrand, L.-G. Acta Chem. Scand. B 34 (1980) 349.

13. Eberson, L. J. Am. Chem. Soc. 105 (1983) 3192.

14. Jönsson, L. Acta Chem. Scand. B 35 (1981) 683.

15. Jönsson, L. Acta Chem. Scand. B 37 (1983) 761.

16. Jönsson, L. and Wistrand, L.-G. J. Chem. Soc. Perkin Trans. 1 (1979) 669.

17. Eberson, L. and Nyberg, K. J. Am. Chem. Soc. 88 (1966) 1686; Accounts Chem. Res. 6 (1973) 106; Tetrahedron 32 (1976) 2185.

18. Eberson, L. J. Am. Chem. Soc. 89 (1967) 4669.

19. Eberson, L. and Nyberg, K. Adv. Phys. Org. Chem. 12 (1976) 1.

20. Eberson, L. Adv. Phys. Org. Chem. 18 (1982) 79.

21. Nyberg, K. and Wistrand, L.-G. Chem. Scr. 6 (1974) 234.

22. Eberson, L. and Jönsson, L. Submitted.

23. Heiba, E.I., Dessau, R.M. and Koehl, W.J., Jr. J. Am. Chem. Soc. 91 (1969) 6830.

24. Kurz, M.E. and Hage, G.W. J. Org. Chem. 42 (1977) 4080.

25. Ellis, S.R., Pletcher, D., Brooks, W.N. and Healy, K.P. J. Appl. Electrochem. 13 (1983) 735; Gourcy, J., Simonet, J. and Jaccaud, M. Electrochim. Acta 24 (1979) 1039; Mastragostino, M., Casalbore, G. and Valcher, S. J. Electroanal. Chem. 56 (1974) 117. 
26. Rollinson, C.L. Compr. Inorg. Chem. 3 (1973) 764.

27. Norman, R.O.C. and Taylor, R. Electrophilic Substitution in Benzenoid Compounds, Elsevier, Amsterdam 1965, Chapter 5.

28. Koehl, W.J. Jr., U.S. Pat. 3.347.758, Mobil Oil Co. (1967).

29. Eberson, L. and Helgée, B. Acta Chem. Scand. B 32 (1978) 157.

30. Baciocchi, E., Mei, S. and Rol, C. J. Org. Chem. 43 (1978) 2919.

31. Baciocchi, E., Rol, C. and Sebastiani, G.V. J. Chem. Res. (S) (1983) 232.

32. Giordano, C., Belli, A., Citterio, A. and Minisci, F. J. Org. Chem. 44 (1979) 2314.

33. Baciocchi, E., Mandolini, L. and Rol, C. Tetrahedron Lett. (1976) 3343.

34. For a comparison between $\mathrm{Co}$ (III)W and radical promoted side-chain acyloxylation, see Wistrand, L.-G. Acta Chem. Scand. 38 (1984) 812.

35. Nyberg, K. Acta Chem. Scand. 24 (1970) 1609.

36. Eberson, L., Jönsson, L. and Wistrand, L.-G. Tetrahedron 38 (1982) 1087.

37. Eberson, L. J. Mol. Catal. 20 (1983) 27.

38. Jönsson, L. and Wistrand, L.-G. J. Org. Chem. 49 (1984) 3340.

39. den Heijer, J., Shadid, O.B., Cornelisse, J. and Havinga, E. Tetrahedron 33 (1977) 779.

Received April 30, 1984. 